\title{
ANALISIS FAKTOR-FAKTOR PENYEBAB DUPLIKASI NOMOR REKAM MEDIS DI RUMAH SAKIT UMUM DAERAH TAIS
}

\author{
Niska Ramadani ${ }^{1}$, Septi Syafitri \\ Akademi Kesehatan Sapta Bakti Bengkulu \\ Email :niskaramadani88@gmail.com
}

\begin{abstract}
Abstrak
Penomoran nomor rekam medis yang baik merupakan salah satu kunci keberhasilan atau kebaikan manajemen rekam medis dari suatu pelayanan kesehatan, tentunya jika didukung dengan sistem yang baik. Sumber daya manusia yang bermutu dan prosedur atau tata kerja yang baik serta sarana atau fasilitas yang memadai. Jenis penelitian yang digunakan pada penelitian ini adalahmetode observasional deskriptif dengan desain cross-sectional, populasi dalam penelitian ini adalah berkas rekam medis pasien rawat jalan di rumah sakit umum daerah tais, dengan sample sebanyak 233 berkas rekam medis dengan teknik pengambilan sample secara Sistematic Random Sampling. Menggunakan data primer dengan cara melakukan wawancara tentang penetapan SOP yang belum ada di tetapkan di bagian unit rekam medis, KIUP yang belum tersedia di unit rekam medis, Pendidikan Rekam Medis dan data sekunder dengan cara melakukan telaah nomor dokumen rekam medis pasien rawat jalan yang tersusun di dalam box, diolah secara univariat. Penelitian ini dilaksanakan pada bulan Mei sampai Juni 2016 di Unit Rekam Medis Rumah Sakit Umum Daerah Tais. Hasil analisa univariat, dari 233 berkas rekam medis $32(13,73 \%)$ terjadi duplikasi penomoran berkas rekam medis, dan 201 (86,26\%) tidak terjadi duplikasi nomor rekam medis. Diharapkan petugas di unit rekam medis agar dapat menjalankan pelayanan yang sesuai dengan kaedah-kaedah yang berlaku yaitu ketersediaan standar operasional prosedur, sarana dan prasarana khususnya KIUP dan sumber daya manusia supaya kejadian duplikasi nomor rekam medis dapat diatasi.
\end{abstract}

\section{Kata kunci : SOP,KIUP, Pendidikan}

\section{PENDAHULUAN}

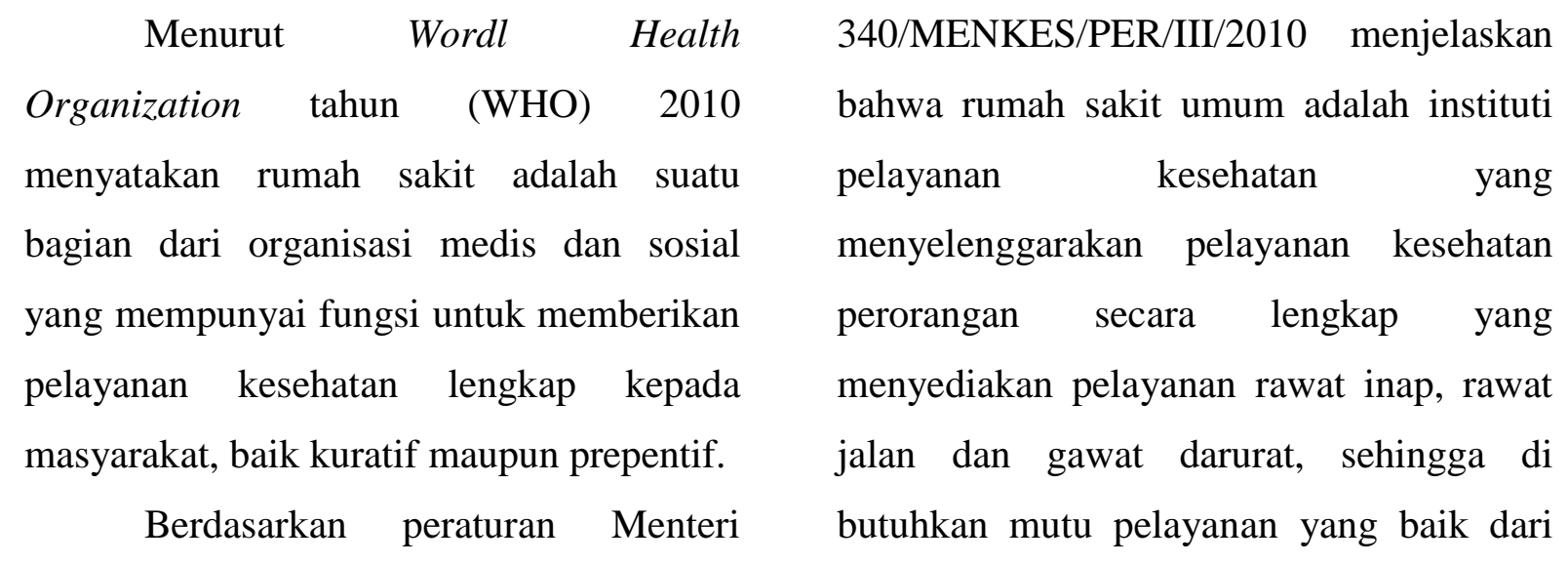

Kesehatan Republik Indonesia No. 
berbagai faktor, salah satunya penyelenggaraan rekam medis.

Pengertian rekam medis menurut PERMENKESNo.269/MENKES/PER/III/2 008 rekam medis adalah berkas berisikan catatan dan dokumen antara lain identitas pasien, hasil pemeriksaan, pengobatan yang telah diberikan, serta tindakan dan pelayanan lain yang telah di berikan kepada pasien, catatan merupakan tulisan-tulisan yang di buat oleh dokter mengenai tindakan-tindakan yang telah dilakukan kepada pasien dalam pelayanan kesehatan.

Menurut (Hatta, 2004) rekam medis merupakan kumpulan fakta tentang kehidupan seseorang dan riwayat penyakitnya, termasuk keadaan sakit, pengobatan saat ini dan saat lampau yang ditulis oleh para praktisi kesehatan dalam upaya mereka memberikan pelayanan kesehatan pada pasien.

Menurut pasal 46 ayat (1) UU No. 29 Tahun 2004 tentang praktik kedokteran, rekam medis adalah berkas yang berisikan catatan dan dokumen tentang identitas pasien, pemeriksaan, pengobatan, dan tindakan lain yang diberikan kepada pasien.

Berkas rekam medis yang berisi data individual yang berisi rahasia, maka setiap lembar formulir berkas rekam medis harus dilindungi secara di masukan ke dalam folder berisi data dan informasi hasil pelayanan yang di peroleh pasien secara individu. Jika pasien berobat ulang, maka berkas rekam medis di ambil kembali untuk sekurang-kurangnya lima tahun sejak pasien berobat terakhir atau berobat pulang dari rumah sakit memeriksaan, pengobatan, dan tindakan lain yang diberikan kepada pasien (Barthos, 2009).

Dalam penyelenggaraan rekam medis terbagi menjadi empat yaitu pendaftaran, penyimpanan, penamaan, sistem penomoran. Setiap pasien yang datang ke unit pelayanan kesehatan diberi satu nomor rekam medis yang berfungsi sebagai satu diantaranya identitas pasien. Setiap pasien hanya mendapatkan satu nomor rekam medis yang dipakai untuk pelayanan rawat jalan maupun pelayanan rawat inap. Sistem penomoran rekam medis berperan penting dalam memudahkan pencarian berkas rekam medis apabila pasien kembali datang berobat di sarana pelayanan kesehatan menurut (Muldiana, 2016).

Menurut (Muldiana, 2016) Dampak duplikasi penomoran berkas rekam medis dapat berakibat pada sulitnya pencarian berkas rekam medis apabila pasien datang kembali berobat.

Duplikasi penomoran menurut Kamus Besar Bahasa Indonesia, duplikasi adalah perulangan, keadaan rangkap, 
sedangkan rangkap adalah dua tiga helai melekat menjadi satu. Menurut Kemenkes RI tahun 2006 dalam rahayu (2013), duplikasi penomoran adalah pengulangan dua tiga kali pencatatan nomor yang sama.

Pemberian Nomor Cara Unit (Unit Numbering System) Istilah yang biasa digunakan adalah "Unit Numbering System", berbeda dengan sistem seri. Didalam sitem pemberian nomor secara unit ini, pada saat pasien datang pertama kali untuk berobat rawat jalan maupun rawat inap (dirawat) maka pasien berobat akan mendapatkan satu nomor rekam medis yang mana nomor tersebut akan dipakai selamanya untuk kunjungan-kunjungan selanjutnya baik untuk rawat jalan, rawat inap maupun kunjungan ke unit-unit penunjang medis dan instalasi lain untuk mendapatkan pelayanan kesehatan disuatu rumah sakit. Berkas rekam medis pasien tersebut akan tersimpan didalam satu berkas dengan nomor pasien, menurut revisi buku pedoman pengelolaan rekam medis (2006).

Berdasarkan hasil dari penelitian Ikka Muldiana 2016 di Rumah Sakit Atma Jaya terjadi duplikasi nomor rekam medis sebanyak 18 sample, dengan faktor-faktor penyebab terjadinya duplikasi nomor rekam medis dikarenakan kualifikasi pendidikan, pengetahuan, dan pengalaman kurang teliti dan kurang mengetahui tentang sistem penomoran rekam medis.

Rumah Sakit Umum Daerah Tais merupakan salah satu rumah sakit pemerintah tipe $\mathrm{C}$ yang ada di Provinsi Bengkulu yang terletak di Kabupaten Seluma, yang menyediakan pelayanan kesehatan untuk masyarakat, jumlah petugas rekam medis Di Rumah Sakit Umum Daerah Tais berjumlah 12 orang petugas, dimana hanya 1 orang petugas yang lulusan D-III perekam medis, 2 orang petugas lulusan S1 kesehatan, 2 orang petugas lulusan $\mathrm{S} 1$ pendidikan, 5 orang petugas lulusan D-III kesehatan dan 2 orang petugas lulusan SMA di ruangan rekam medis di Rumah Sakit Umum Daerah Tais.

Berdasarkan survei awal yang penulis lakukan di Rumah Sakit Umum Daerah Tais dan setelah dilakukan wawancara dengan petugas rekam medis bahwa pada sistem penomoran berkas rekam medis pasien rawat jalan di Rumah Sakit Umum Daerah Tais dengan cara unit (Unit Numbering System). Namun sering terjadi duplikasi penomoran berkas rekam medis, dimana ditemukan nomor rekam medis yang sama dengan identitas yang berbeda, dikarenakan kondisi tempat penyimpanan berkas rekam medis rawat jalan tahun 2015 yang masih belum tertata 
dengan rapi, berdasarkan data yang diperoleh dari hasil observasi di RSUD Tais dari 7 Box terdapat 700 berkas rekam medis dan 105 ditemukan berkas rekam medis yang terjadinya duplikasi penomoran.

\section{METODE}

Jenis penelitian ini adalah Observasional Deskriptif dengan rancangan cross-sectional. Penelitian Observasional adalah penelitian yang dilakukan dengan cara observasi, pengamatan dan pengukuran terhadap variabel yang diteliti. yang menjadi populasi adalah petugas RM dan seluruh berkas rekam medis sebanyak 700 berkas rekam medis pasien rawat jalan di Rumah Sakit Umum Daerah Tais Tahun 2015 yang mengalami duplikasi penomoran.

Teknik pengambilan sampel ada 2 yaitu yang pertama untuk mengetahui data yang ingin diambil yaitu pendidikan dan ketersedianya KIUP dengan cara mewawancarai 1 orang petugas kepala ruangan rekam medis dan memilih responden secara total sampling yaitu memilih responden berdasarkan pada pertimbangan subyektifnya, bahwa responden tersebut dapat memberikan informasi memadai untuk menjawab pertanyaan penelitian. Yang ke dua untuk mengetahui berkas rekam medis yang terduplikasi dengan menggunakan rumus Stratified Random Sampling yaitu pengambilan sampel dimana populasi yang bersifat heterogen dibagi dalam lapisanlapisan (stara). Jumlah populasi berkas rekam medis dalam satu rak terdapat 7 box berjumlah 700 BRM. Berdasarkan perhitungan sampel didapatkan jumlah sampel 233 BRM yang akan diteliti.

Dalam penyajian data dilakukan analisis secara univariat yaitu distribusi frekuensi dan narasi. Analisis univariat bertujuan untuk menjelaskan/mendeskripsikan karakteristik masing-masing variabel (Hastono, 2007).

Analisa data ini menggunakan tabel dan narasi. Data tentang SOP, pendidikan, KIUP disajikan secara narasi, data duplikasi dalam bentuk tabulasi

\section{HASIL}

\section{Gambaran Umum Rekam Medis RSUD Tais}

Dari hasil wawancara dengan kepala ruangan rekam medis di ketahui bahwa pada bagian rekam medis di RSUD Tais memiliki 12 tenaga petugas rekam medis dengan latar belakang pendidikan 1 orang petugas lulusan DIII rekam medis, 2 orang petugas tamatan S1 kesehatan, 2 orang petugas 
tamatan S1 pendidikan, 5 orang petugas tamatan D-III kesehatan, 2 orang petugas tamatan SMA.

\section{Analisis Data}

Tabel 1 Data Petugas Pendidikan di Ruang Rekam Medis

\begin{tabular}{lcc}
\hline Pendidikan & Jumlah & $\%$ \\
\hline D-III Rekam Medis & 1 & $8,3 \%$ \\
\hline S1 Kesehatan & 2 & $16,6 \%$ \\
\hline S1 Pendidikan & 2 & $16,6 \%$ \\
\hline D-III Kesehatan & 5 & $41,6 \%$ \\
\hline SMA & 2 & $16,6 \%$ \\
\hline Total & 12 & $100 \%$ \\
\hline
\end{tabular}

Tabel 2 Gambaran kejadian duplikasi penomoran berkas rekam medis di Rumah Sakit Umum Daerah Tais.

\begin{tabular}{lcc}
\hline \multicolumn{1}{c}{ Variabel } & $\begin{array}{c}\text { Jumlah } \\
(\mathbf{n})\end{array}$ & \\
& 32 & $13.73 \%$ \\
\hline Duplikasi & 201 & $86.26 \%$ \\
\hline Tidak Duplikasi & \\
\hline
\end{tabular}

Berdasarkan tabel 2 di atas dari 7 box yang diamati dengan jumlah sample 233 berkas rekam medis di ruangan penyimpanan di dapatkan bahwa yang terjadi duplikasi nomor rekam medis sebanyak $32(13,73 \%)$ dan yang tidak mengalami duplikasi nomor berkas rekam medis sebanyak $201(86,26 \%)$.

\section{Ketersediaan SOP Di Bagian Penyimpanan}

Pada Rumah Sakit Umum Daerah Tais diketahui bahwa sistem penomoran yang digunakan adalah straight numbering system atau sistem penomoran secara langsung namun dalam melaksanakan pengelolaan penomorannya belum terlaksanakan dengan baik karena pada Rumah Sakit Umum Daerah Tais belum tersedianya standar operasional prosedur untuk penomoran. Hal ini mengakibatkan tidak adanya keseragaman dalam memberikan nomor terhadap rekam medis sehingga dapat mengakibatkam duplikasi penomoran berkas rekam medis.

\section{Ketersediaan KIUP Di Unit}

\section{Penyimpanan}

Di Rumah Sakit Umum Daerah Tais juga belum tersediannya KIUP. Hal ini dikarenakana standar operasional prosedur dalam pengembangan sarana prasarana belum ada dan kurangnya pengetahuan petugas rekam medis di RSUD Tais, tentang kartu indeks utama pasien (KIUP). Dengan tidak adanya KIUP ini maka petugas akan kesulitan dalam melayani pasien yang tidak membawa kartu berobat, dan petugas memberi 
nomor baru kepada pasien, maka dari itu terjadinya duplikasi berkas rekam medis.

\section{Jumlah SDM Di Bagian Rekam} Medis

Lulusan D-III perekam medis dan informasi kesehatan juga pada Rumah Sakit Umum Daerah Tais masih sangat sedikit sehingga pengetahuan tentang penomoran rekam medis masih sangat terbatas dan petugas di unit rekam medis karena keterbatasan biaya dan karena di Rumah Sakit Umum Daerah Tais kebanyakan lulusan dari bidan ,perawatan, dan SMA sehingga kepedulian terhadap rekam medis masih sangat kurang. Akibatnya indikasi duplikasi nomor rekam medis bisa terjadi.

\section{PEMBAHASAN}

\section{Gambaran Standar Operasional Prosedur (SOP) Terhadap Duplikasi Penomoran Berkas Rekam Medis}

Dari hasil yang diamati di RSUD Tais belum tersedianya SOP (Standar Prosedur Operasional) tentang penomoran berkas rekam medis, hal ini dapat mengakibatkan petugas belum mengetahui langkah apa saja dan tata cara yang harus dilakukan dalam memberi nomor rekam medis .

Standar operasional prosedur dibuat berdasarkan kebijakan dari instalasi Rumah Sakit sendiri dengan ketetapan dari PERMENKES No. 269/MENKES/PER/III/2008 tentang Rekam Medis, yang menyatakan bahwa di setiap unit pelayanan rekam medis harus memiliki standar operasional prosedur (SOP). Sistem penomoran di unit rekam medis merupakan salah satu bagian penting dalam melakukan registrasi pasien, karena sistem penomoran merupakan salah satu identitas pasien, yang membedakan antara pasien satu dengan pasien yang lain. Maka standar operasional prosedur tentang penomoran harus ditetapkan agar terciptanya pelayanan yang baik dan sesuai dengan kaedah-kaedah atau standar yang berlaku di pengelolaan rekam medis bagian penomoran registrasi pasien dan menimalisir terjadinya duplikasi penomoran rekam medis.

2. Gambaran Penggunaan KIUP Terhadap Duplikasi Penomoran Berkas Rekam Medis 
Pada RSUD Tais belum tersedianya KIUP. Hal ini dikarenakan standar operasional prosedur dalam pengembangan sarana prasarana belum ada dan kurangnya pengetahuan petugas rekam medis di RSUD Tais, tentang kartu indeks utama pasien (KIUP).

Menuriut (Robetty, 2015) dalam mempermudah pencarian berkas rekam medis maka diperlukan suatu alat yang dapat membantu petugas untuk penghematan waktu dalam pencarian berkas. Alat tersebut adalah KIUP atau kartu indeks utama pasien, KIUP adalah suatu kartu katalog yang berisikan nama semua penderita yang pernah berobat kerumah sakit. Informasi yang terkandung dalam KIUP merupakan kunci untuk menemukan berkas rekam medis pasien. Dengan tidak adanya KIUP ini maka petugas akan kesulitan dalam melayani pasien yang tidak membawa kartu berobat, dan petugas memberi nomor baru kepada pasien, maka dari itu terjadinya duplikasi berkas rekam medis.

3. Gambaran Sumber Daya Manusia Pendidikan Rekam Medis Terhadap

\section{Duplikasi Penomoran Berkas}

\section{Rekam Medis}

Dari hasil observasi terhadap Kepala Rekam Medis di RSUD Tais Petugas rekam medis berjumlah 12 orang. Masing-masing 2 orang petugas tamatan S1 kesehatan, 2 orang petugas tamatan S1 pendidikan, 5 orang petugas tamatan D-III kesehatan, 2 orang petugas tamatan SMA dan ada 1 orang petugas yang lulusan D-III perekam medis. Dengan minimnya petugas yang berkualifikasi pendidikan rekam medis, maka dapat menjadi faktor terjadinya duplikasi penomoran rekam medis, hal ini dikarenakan petugas kurang mengetahui dan kurang memperhatikan tentang sistem penomoran rekam medis.

Pendidikan adalah suatu usaha mengembangkan kepribadian dan kemampuan di dalam dan di luar sekolah dan berlangsung seumur hidup. Pendidikan mempengaruhi proses belajar, makin tinggi pendidikan seseorang makin mudah orang tersebut untuk menerima informasi. Dengan pendidikan tinggi maka seorang akan cenderung untuk mendapatkan informasi yang masuk semakin banyak pula pengetahuan yang didapat tentang kesehatan. Pengetahuan sangat erat 
kaitannya dengan pendidikan tinggi maka orang tersebut akan semakin luas pengetahuannya. Namun perlu ditekankan bahwa seorang yang berpendidikan rendah tidak berarti mutlak pengetahuan rendah pula. Peningkatan pengetahuan tidak mutlak diperoleh di pendidikan formal, akan tetapi juga dapat diperoleh pada pendidikan non formal. Pengetahuan seseorang tentang suatu objek tertentu. Semakin banyak aspek positif dari objek yang diketahui, akan menimbulkan sikap positif terhadap objek tertentu (Notoadmojo, 2010).

\section{SIMPULAN}

Dengan diketahuinya ada 32 nomor rekam medis terjadi duplikasi (13.73\%) dari 233 berkas rekam medis yang di teliti di Rumah Sakit Umum Daerah Tais. Hal ini dikarenakan factor :

1. Belum tersedianya SOP Tentang penomoran, yang dapat digunakan untuk panduan dan pedoman dalam memberi nomor rekam medis.

2. Sarana dan prasarana khususnya KIUP di unit penyimpanan berkas rekam medis belum ada.

3. Dalam penyelenggaraan rekam medis hanya 1 orang petugas lulusan dari DIII perekam medis dan informasi kesehatan, 2 orang petugas tamatan S1 kesehatan, 2 orang petugas tamatan $\mathrm{S} 1$ pendidikan, 5 orang petugas tamatan D-III kesehatan, dan 2 orang petugas tamatan SMA.

\section{DAFTAR PUSTAKA}

Barthos. B. (2009). Berkas Rekam Medis. Jakarta: PT. Bumi Aksara

Faiqatul Hikmah. 2013.Analisis Faktor Faktor Penyebab Duplikasi Nomor Rekam Medis Dirtjmah Saiflt Daerah Balun\&Jember Periode 2012. Daerah Balung Jember:.Jurnal Politeknik Negeri Jember.

Keputusan Menteri Kesehatan Republik Indonesia No.269/MENKES/PER/III/2008. Pengertian Rekam Medis. di unduh http://scholargoogle.co.id. Jakarta.

Keputusan Menteri Kesehatan Republik Indonesia No.340/MENKES/PER/III/2010.

Tentang Ruah Sakit di unduh http://scholargoogle.co.id. Jakarta

Muldiana ika. 2016. Analisis Faktor_Faktor Penyebab Duplikasi Nomor Rekam Medis.Rumah Sakit Atma Jaya. Daerah Jakarta. Jurnal Universitas Esa Unggul Jakarta

Mulya A. H. (2006). Pedoman Penyelenggaraan dan Prosedur Rekam Medis Rumah Sakit di Indonesia. Jakarta

Notoatmodjo. 2010. Metodologi Penelitian Kesehatan. Jakarta : PT. Rineka Cipta

Peraturan Menteri Pendayagunaan Aparatur Negara dan Reformasi ,Birokrasi.Nomor 30 Tahun 2013.Jabatan Fungsional Perekam Medis dan Angka Kreditnya

Rumah Sakit Umum Daerah Tais. 2014. Profil RSU Tais Tahun 2016 
Riwidikdo, handoko. (2009). Statistik Kesehetan. Belajar mudah teknik analisis data dalam Penelitian Kesehatan. Yogyakarta: Mitra Cendikia Press.

Rustiyanto. E. (2009). Rekam Medis. Yogyakarta: Graha Ilmu

R, Hatta. (2013). Pedoman Manajemen Informasi Kesehatan di Sarana Pelayanan Kesehatan. Jakarta: Universitas Indonesia

Robetty, R (2015). Sistem kiup. Jurnal Ilmiah Perekam dan Informasi Kesehatan Imelda. Daerah bangkatan Binjai

Sastroasmoro, Sudigdo, dan Sofyan Ismael, 2010. Dasar-Dasar Metodologi Penelitian Klinis edisi ketiga. in: Pemilihan Subyek Penelitian dan Desain Penelitian. Jakarta: Sagung Seto.

Undang-undang No. 44 Tahun 2009. Tentang Rumah Sakit. Pasal 52 Ayat 1, Jakarta. di unduh http://scholargoogle.co.id

World Health Organization, (2010). Global Physical Activity Surveillance. Available from:

http://www.who.int/chp/steps/GPAQ/en/i ndex.html. 